\title{
The Transition to Parenthood as a Critical Window for Adult Health
}

\author{
Darby Saxbe \\ University of Southern California
}

\author{
Maya Rossin-Slater \\ Stanford University School of Medicine
}

\author{
Diane Goldenberg \\ University of Southern California
}

\begin{abstract}
Becoming a parent is a transformative experience, marked by hormonal changes and neuroplasticity as well as shifts in self-concept, social roles, and daily routines. Although the arrival of a new baby is often a joyful event, the postpartum period can also be a time of heightened psychosocial stress and health behavior changes, including significant sleep disruption and decreased physical activity. Markers of allostatic load, such as physiological stress and inflammation, may also become dysregulated during this time. Given these neurobiological, psychosocial, and behavioral changes, the transition to parenthood may shape health trajectories in midlife. For many mothers and fathers, the transition to parenthood represents an inflection point for obesity, such that perinatal weight gains are retained long-term. Similarly, many individuals experience their 1st episode of major depression during the postpartum period. In sum, the transition to parenthood may represent a critical window for determining both mental and physical health in midlife and beyond. Physical and mental health problems over the transition to parenthood may be exacerbated for parents without access to protected, paid time off from employment. Known disparities in mood disorders, obesity, and allostatic load may be linked to risk factors stemming from the perinatal period. This article relates the importance of the transition to parenthood to population health and discusses parental leave policy as an example of an initiative that can support parents and relieve stress during the perinatal period.
\end{abstract}

Keywords: parents, postpartum, depression, weight, paid family leave

The birth of a child also occasions the birth of that child's parents. Increasingly, researchers and policymakers have recognized the impact of early childhood experiences on long-term well-being. Just as a child's brain and body undergoes dramatic growth during infancy, so, too, do parents experience transformative change as they learn how to

Editor's note. Darby Saxbe received a 2018 APA Award for Distinguished Scientific Early Career Contributions to Psychology. This article is based on an invited presentation at the 126th Annual Convention of the American Psychological Association, held August 9-12, 2018, San Francisco, California.

Authors' note. Darby Saxbe, Department of Psychology, University of Southern California; Maya Rossin-Slater, Department of Health Research and Policy, Stanford University School of Medicine; Diane Goldenberg, Department of Psychology, University of Southern California.

I would like to thank my funding source-NSF CAREER Award 1552452 to Darby Saxbe.

Correspondence concerning this article should be addressed to Darby Saxbe, Department of Psychology, University of Southern California, 3620 McClintock Boulevard, Los Angeles, CA 90089. E-mail: dsaxbe@usc.edu nurture and care for their infant. The transition to parenthood represents a time of sensitivity, risk, and opportunity not just for the new baby but for the whole family. In this article, we describe how the transformations that occur over the transition to parenthood intersect with determinants of life span health, and use paid family leave (PFL) as an example of a policy that may promote public health.

The transition to parenthood represents a nexus of many co-occurring biological, psychological, social, economic, and behavioral changes. Although the arrival of a new baby is often celebrated as a joyful event, new adoptive or biological parents may encounter significant sleep disruption (Hagen, Mirer, Palta, \& Peppard, 2013); heightened psychosocial stress (Reid \& Taylor, 2015); vulnerability to mood disorders (Paulson \& Bazemore, 2010); and changes in physical health, including weight gain or retention (Umberson, Liu, Mirowsky, \& Reczek, 2011) and changes in immune and inflammatory function (Denney et al., 2011). For many mothers and fathers, the transition to parenthood represents an inflection point for obesity, such that perinatal weight gains are retained long-term and lead to increased lifetime risk of cardiovascular disease and diabetes (Um- 
berson et al., 2011). Similarly, many individuals experience their first episode of major depression during the postpartum period (Stowe \& Nemeroff, 1995), which may have a kindling effect, increasing the risk for future depressive episodes (Monroe \& Harkness, 2005).

Despite the high importance of parents to the health of children, families, and societies, the United States is one of few countries without any statutory national paid family leave provisions for new parents (only Suriname and Papua New Guinea share this distinction) and is the only developed country without a PFL policy. An astonishing one quarter of mothers in the United States return to work within 2 weeks of delivering an infant (U.S. Department of Labor, 2012). For the majority of American parents of infants who participate in the labor force (Bureau of Labor Statistics, 2015), PFL can help new parents balance competing work and family responsibilities by providing them with wageprotected time off work. In contrast, short or nonexistent parental leave can challenge working parents by increasing time demands and role conflict for parents who must juggle paid work and parenting and by compromising parents' ability to maintain health-protective behaviors, such as sleep and exercise. Although these challenges may heighten the risk of physical and mental health problems over the transition to parenthood, research examining the effects of PFL on parental well-being has been relatively sparse.

Economists who have studied parental leave have focused primarily on the effect of these policies on worker wages and retention. However, as we argue in this article, parental leave is not just a workforce issue but a public health one. Given the many changes that occur over the transition to parenthood, policies that relieve stress on new parents can have outsize impact on long-term health trajectories and help to redress population-level health disparities. In the following sections, we describe three domains of transformation across the transition to parenthood that might play a mechanistic role in health: neurobiological change, psychosocial change, and behavioral change (specifically, changes in health behaviors, including sleep and exercise). Next, we outline three areas of potentially heightened health risk in new parents: allostatic load, obesity, and mood disorders. We then discuss research on PFL in conjunction with family health.

\section{Mechanisms of Health and Well-Being Across the Transition to Parenthood}

\section{Neurobiological Change}

The role of neuroplasticity in development. During "critical windows" that include infancy and adolescence, the brain appears to undergo particularly pronounced reorganization, or plasticity, as it prepares for new developmental milestones. This reorganizing of neural circuitry differs from neurogenesis, a process that refers to the formation of new neurons and whose occurrence in the adult human brain has recently come under scrutiny (Sorrells et al., 2018). The brain is not fixed and immutable after childhood, and neuroplasticity allows individuals to adapt to changing environmental demands. For example, an appreciation for adolescence as a time of significant neural remodeling has emerged, fueling renewed scientific and popular interest in this developmental period (Fuligni, Dapretto, \& Galván, 2018). The brain changes of adolescence co-occur with the hormonal events of puberty, and animal research has suggested that sex hormones may promote organizing effects on the brain during this time (Sisk \& Zehr, 2005). Although direct causality between puberty and neuroplasticity cannot be established in human research, longitudinal studies have suggested that pubertal hormones may sculpt the developing brain (Wierenga et al., 2018). Renewed focus on neuroplasticity has informed an understanding of the adolescent brain as sensitive to input and intervention, promoting change at multiple levels, from public policy to the juvenile justice system. Similarly, the transition to parenthood is marked by dramatic shifts in roles, motivations, and sex hormones. If the transition to adolescence may open a "second window of opportunity" (Dahl et al., 2017) for intervention, the transition to parenthood may open a third.

Parenthood as a potential period of neuroplasticity. The transition to parenthood is a time of transformation in both behavior and biology. Extensive work in rodents has laid the foundation for current understanding of this period as one in which the hormonal surges that accompany pregnancy contribute to neural remodeling to support adaptive parenting behaviors (Brunton \& Russell, 2008). Research on human parents has been more limited by a lack of prospective and longitudinal research, but a growing literature has explored the parenting brain. Much of this research has been conducted in mothers, given the overt hormonal events of pregnancy. However, because nonessential magnetic resonance imaging techniques are typically discouraged in pregnant women, the majority of research examining plasticity in the human maternal brain has been confined to changes that occur during the postpartum period (reviewed by Kim, Strathearn, \& Swain, 2016). For example, when images of mothers' brains were acquired 2-4 weeks postpartum and then again at 3-4 months postpartum, gray matter increases were found in regions including the hypothalamus, substantia nigra, and amygdala, and these increases were related to mothers' positive perception of their baby (Kim et al., 2010).

One recent study has expanded the time line of evidence to include pregnancy as a potential catalyst for neural changes in new mothers (Hoekzema et al., 2017). In this novel design, a prospective study was conducted involving primiparous (first-time) biological mothers compared to nulliparous women to investigate whether pregnancy is 
associated with changes in gray matter structure of the human brain (Hoekzema et al., 2017). Significant reductions in gray matter were associated with pregnancy, primarily in areas of the cortex known to play a key role in social processes such as cortical midline structures (medial frontal cortex, anterior cingulate cortex, precuneus and posterior cingulate cortex) and the lateral prefrontal and temporal cortex. These changes significantly predicted the quality of maternal attachment in the postpartum period. Findings of gray matter decreases are not necessarily incongruous with the previously described reports of gray matter increases during the postpartum period (Kim et al., 2010). Neuroplasticity can reflect any number of processes that thicken or thin the gray matter architecture of the brain, including the refining, severing, or forging of neural connections.

It is interesting that Hoekzema and colleagues (2017) also used fathers as a control group of parents who undergo the experiential changes of parenthood but do not participate in the hormonal events of pregnancy. Despite these biological differences, fathers have been shown to engage neural circuitry to infant-related stimuli that is strikingly similar to that in mothers (Swain, Lorberbaum, Kose, \& Strathearn, 2007), and research has demonstrated that male individuals do undergo significant hormonal change during the transition to parenthood. For example, compared to nonfathers, they exhibit longitudinal decreases in testosterone after becoming parents, and among fathers, lower levels of testosterone are associated with greater involvement in caregiving (Gettler, McDade, Feranil, \& Kuzawa, 2011). At a neural level, testosterone in fathers has been linked to activation in the caudate, a key reward-related region, when viewing images of their own infant (Kuo, Carp, Light, \& Grewen, 2012), suggesting an association between hormones and neural control of motivation in fathers. To date, the only other longitudinal study of fathering-related changes in the brain, besides that by Hoekzema and colleagues (2017), has found volumetric increases in the striatum, hypothalamus, amygdala, and prefrontal cortex from 1 to 4 months postpartum (Kim et al., 2014). An intriguing cross-sectional study found that fathers in gay couples who were primary caregivers of an infant showed different neural responses to videotaped parent-child interactions than did secondary caregiver fathers, suggesting that the extent of parenting experience may also shape paternal brain function (Abraham et al., 2014). Similar results might be found in adoptive mothers, but, to our knowledge, no other studies on the adoptive parental brain have yet been published.

Many studies of neurobiology in new parents have relied on small, nondiverse samples, but more diverse samples will shed light on how context affects the transition to parenthood. Socioeconomic disadvantage has been associated with differences in neural processing of infant stimuli, including cry sounds and infant faces (Kim, Capistrano, \&
Congleton, 2016; Kim, Capistrano, Erhart, Gray-Schiff, \& $\mathrm{Xu}, 2017)$. For example, first-time mothers with lower income showed reduced responses to infant cry sounds in emotion processing regions that were mediated by perceived stress (Kim, Capistrano, \& Congleton, 2016). Another study found dampened amygdala responses to positive infant faces and elevated amygdala responses to negative infant faces in low-income mothers compared to mothers with higher income, and these amygdala responses were associated with intrusive maternal behavior (Kim et al., 2017). Although these studies have not specifically examined the role of PFL, it is possible that differences in the timing of the return to work contributed to these apparent socioeconomic differences in the parenting brain.

\section{Psychosocial Change}

In the 1950s, LeMasters identified the transition to parenthood as a "crisis event" for marriage (LeMasters, 1957), and decades of subsequent research have examined challenges to romantic relationship quality and psychological well-being during this time (Belsky \& Rovine, 1990; Cowan \& Cowan, 2000; Rhoades, Stanley, \& Markman, 2012; Rossi, 1968). Infants require around-the-clock care, which creates time demands (particularly in the absence of protected time off from work), emotional and cognitive demands (because infants need both attention and affection), relationship demands (because the romantic relationship takes a backseat to parenting), and financial demands (because parents must pay for childcare or absence from work (Marshall \& Tracy, 2009; Moen \& Orrange, 2002). Given these many new demands, it is unsurprising that the transition to parenthood can be accompanied by shifts in identity, relationship roles, and daily routines that may be experienced as challenging upheavals. A longitudinal study of almost 85,000 Norwegian mothers found that both maternal self-esteem and relationship quality showed longitudinal declines in the years following the birth of the first child (van Scheppingen, Denissen, Chung, Tambs, \& Bleidorn, 2018). Another large longitudinal study found that becoming a parent was associated with a greater decline in happiness than were other life events, such as divorce, unemployment, and the death of a partner (Margolis \& Myrskylä, 2015). Significant stress in men over the transition to fatherhood has also been observed within multiple studies (Genesoni \& Tallandini, 2009).

The term stress encompasses not just stressful life events but individuals' responses to them (Harkness \& Monroe, 2016). Although periods of high stress exposure are typically associated with higher stress responses, personality traits and preexisting vulnerabilities can also shape stress responses (Harkness \& Monroe, 2016). The transition to parenthood brings both normative stress exposures and individual differences in stressful experiences. For example, 
although infant care can be taxing for all new parents, infants with difficult temperaments or developmental disabilities can bring extra challenges (Belsky \& Rovine, 1990; Vik et al., 2009). In addition to infant temperament, other factors like the neurobiological changes described in the previous section and the behavioral changes described in the next section may interact with psychosocial challenges. Moreover, parents whose return to work is hastened by financial pressures or job insecurity may struggle more to juggle the new demands of parenting and to balance their occupational role with their new role as parents, creating conflict and ambivalence about both work and parenthood (Moen \& Orrange, 2002). Therefore, access to PFL may be another important source of individual differences in psychosocial stress over the transition to parenthood, one that has been surprisingly understudied by psychologists.

\section{Behavioral Change}

Not only do new parents' brains, bodies, and relationships change, so do health behaviors within a number of domains. For example, compared to the general population, parents of infants are significantly more likely to report insufficient sleep. Specifically, the amount of sleep lost to nighttime infant care demands has been estimated at $80 \mathrm{hr}$ a year for the first few years of a child's life (Hagen et al., 2013). An actigraphy study found that, on average, 1-year-old infants had six-seven wakings per night and were awake an average of $2 \mathrm{hr}$ (Acebo et al., 2005). Although mothers tend to intervene more often during night wakings, fathers also wake up routinely with infants. In fact, fathers may actually get less total sleep than mothers in the early postpartum period, in part because mothers report more daytime sleep (Gay, Lee, \& Lee, 2004). It is unsurprising that many new parents report excessive daytime sleepiness that interferes with daily functioning and may compromise their ability to participate successfully in paid work during the first year postpartum (Filtness, MacKenzie, \& Armstrong, 2014).

Only a few studies have examined how the transition to parenthood affects health behaviors beyond sleep, but there is some evidence that behaviors such as eating and physical activity may be affected by the transition to parenthood. Parents are less physically active than are nonparents, perhaps because childcare demands reduce opportunities for leisure and because fatigue from poor sleep may diminish the motivation to exercise (Bellows-Riecken \& Rhodes, 2008). New parents spend about five fewer hours a week exercising than do nonparents (Hull et al., 2010) and engage in less vigorous activity (Rhodes et al., 2014). New mothers appear to consume more sugar-sweetened beverages and saturated fats than do similarly aged women who are not mothers (Berge, Larson, Bauer, \& Neumark-Sztainer, 2011), whereas first-time fathers have higher bread consumption than do nonfathers (Nasuti et al., 2014). Both neurobiological and psychosocial changes likely interact with these behavioral changes: For example, psychological stress is bidirectionally linked with sleep and exercise, and exhaustion from lost sleep may spill over to compromise health behaviors (such as exercise) and affect relationship quality. These three intertwined areas of change work together to increase health risks including allostatic load, obesity risk, and mood disorder risk.

\section{Areas of Heightened Health Risk Vulnerability Across the Transition to Parenthood}

\section{Allostatic Load}

Allostatic load, or the "wear and tear" on the body caused by chronic stress, describes the cumulative physical health toll of repeated adaptation to stress across multiple systems. The body strives to stay in balance around a homeostatic set point, but, like elephants on a seesaw, repeated stressors can challenge this balancing act and create regulatory costs (Sapolsky, 2004). Allostatic load has been quantified using indices of cardiometabolic and immune-inflammatory function and may predict long-term health and mortality risk (Seeman, McEwen, Rowe, \& Singer, 2001). Many studies have found allostatic load to be linked with the constructs described in this article, including psychosocial stress, sleep, and mental health (e.g., Juster, McEwen, \& Lupien, 2010). Few studies have specifically measured changes in markers of allostatic load across the transition to parenthood, but changes in stress system functioning and inflammation during this time may reflect accumulating allostatic load that portends disease outcomes in midlife and beyond.

Levels of the stress hormone cortisol increase steeply in biological mothers in late pregnancy as part of the body's preparation for childbirth, and paternal cortisol may rise in late pregnancy and the early postpartum period as well (Storey, Walsh, Quinton, \& Wynne-Edwards, 2000). Prenatal cortisol has been associated with stress and social support, and dysregulated profiles of diurnal cortisol during pregnancy have been found to predict gestational outcomes such as birth weight (Guardino et al., 2016). Few studies have specifically examined stress physiology during the postpartum period, but studies focusing on the parents of older children have found factors such as household labor, relationship distress, work worries, and work-family conflict to be associated with suboptimal cortisol patterns (Saxbe, Repetti, \& Graesch, 2011; Slatcher, Robles, Repetti, \& Fellows, 2010). Breastfeeding has also been linked with healthier profiles of diurnal cortisol in postpartum mothers (Simon, Adam, McKinney, Krohn, \& Shalowitz, 2016). In sum, both the physiology of pregnancy, birth, and breastfeeding and the stress of the transition to parenthood may affect the functioning of physiological stress systems. Ma- 
ternal prenatal cortisol may, in turn, influence offspring brain and physical development (reviewed by Zijlmans, Riksen-Walraven, \& de Weerth, 2015). In a related vein, linkage in couple cortisol levels have been noted in both laboratory-based and daily diary studies, including studies of new parents, suggesting that paternal cortisol patterns may entrain with mothers during the transition to parenthood (Saxbe et al., 2015). This linkage may become heightened within contexts of relationship distress (Saxbe et al., 2015). However, the implications of couple hormonal coregulation for health in new parents have not been thoroughly explored.

The maternal immune system also changes during pregnancy so that the mother can tolerate the fetus but still ward off infection (Denney et al., 2011). Studies have reported both decreases and increases in proinflammatory cytokines during pregnancy (Denney et al., 2011; Gillespie, Porter, \& Christian, 2016), and these immune changes may also be influenced by psychosocial stress and by health behaviors. In a sample of mostly low-income women assessed at 2-3 months postpartum, greater proinflammatory cytokine production was linked with parenting stress, perceived stress, depressive symptoms, and poor sleep quality, but only among the African American women in the sample (Christian, Kowalsky, Mitchell, \& Porter, 2018). Moreover, sleep mediated the association between stress-distress and inflammatory markers, and stress-distress mediated the association between sleep and inflammatory markers, suggesting bidirectional relationships between all of these constructs. Another study found that financial stress predicted higher levels of postpartum inflammation in lowincome mothers (Guardino et al., 2017). In sum, the transition to parenthood is a potentially dynamic window for stress physiology and inflammation, and these markers of allostatic load may interact with changing levels of psychosocial stress, sleep, and exercise. Although there is a large literature on the causes and consequences of allostatic load in midlife, few studies have concentrated specifically on the perinatal period.

\section{Obesity}

The transition to parenthood may represent an inflection point for body weight trajectories in both men and women (Umberson et al., 2011). About 50\% of women remain above their prepregnancy weight at 1 year postpartum, and gestational weight gain predicts body mass index (BMI) even 15 years later (Amorim, Rössner, Neovius, Lourenço, \& Linné, 2007). Fathers also appear to gain weight over the transition to parenthood and show steeper longitudinal weight-gain trajectories, with fathers weighing, on average, 14 pounds more than do similarly aged childless men (Umberson et al., 2011).
Hormonal changes over the transition to parenthood have been associated with weight-gain risk for both mothers and fathers. For example, lower levels of testosterone explain greater abdominal adiposity among partnered men living with children, compared to single, childless men (Gettler, Sarma, Gengo, Oka, \& McKenna, 2017). In women, flatter diurnal cortisol slopes, a marker of allostatic load that may indicate compromised physiological adaptation to psychosocial stress, have been associated with postpartum weight retention (Straub et al., 2016). Despite these intriguing findings, the literature connecting perinatal hormones to body weight is small and has neglected fathers.

Psychosocial stress has been associated with weight gain over the transition to parenthood (Hill et al., 2013). A birth cohort study of over 37,000 Danish mothers of infants found that psychological distress, low socioeconomic status (SES), work stress, and work-family conflict all predicted higher postpartum weight retention (Pedersen et al., 2011). Other work has found that both depression and life stress predict higher maternal weight retention in early parenthood (Whitaker, Young-Hyman, Vernon, \& Wilcox, 2014). Changes in sleep and exercise may also heighten the risk of postpartum weight retention. Several studies have found that shorter postpartum maternal sleep duration predicts higher weight retention, particularly among younger, low-SES women (e.g., Siega-Riz et al., 2010). However, the literature on sleep and weight changes across the transition to parenthood is small, and no studies have included fathers (Xiao et al., 2014). Breastfeeding is also an important determinant of maternal postpartum weight. Exclusive breastfeeding for at least 6 months can essentially eliminate gestational weight gain (Baker et al., 2008). However, only $19 \%$ of U.S. women exclusively breastfeed at 6 months, and returning to work before 6 months predicts shorter breastfeeding duration (Scott, Binns, Oddy, \& Graham, 2006), suggesting that PFL access may play an important role in postpartum weight retention.

\section{Mood Disorders}

Mood disorders have been identified as the most common medical complication of pregnancy and the postpartum period (Marcus, 2009). Among mothers, prevalence estimates for postpartum depression (PPD) range from $10 \%$ to $20 \%$ in developed countries (O'Hara \& McCabe, 2013). New fathers also report depressive symptoms at roughly twice the rate of men in the general population (Paulson \& Bazemore, 2010). Both maternal and paternal PPD have well-established, long-lasting negative effects on child and family well-being (Murray \& Cooper, 1997; Ramchandani, Stein, Evans, O'Connor, \& The ALSPAC Study Team 2005).

Postpartum depression may be subserved by a unique neurobiological profile. For example, depressed mothers 
have shown blunted neural activation to infant stimuli in a variety of neural regions linked with emotion processing and emotion regulation (Laurent \& Ablow, 2013). Similarly, maternal depression was linked with heightened amygdala activation to unfamiliar babies (Wonch et al., 2016), perhaps due to dampening of the neural activation to their own infant. Furthermore, mothers with weaker connectivity between the amygdala and insula reported greater symptoms of depression, whereas those with stronger connectivity were more responsive to their newborns. Both maternal and paternal postpartum depression has been linked with hormones that appear to change over the transition to parenthood, including testosterone, prolactin, and oxytocin (Yim, Tanner Stapleton, Guardino, HahnHolbook, \& Dunkel Schetter, 2015). For example, Saxbe, Dunkel Schetter, Simon, Adam, and Shalowitz (2017) found that low postpartum testosterone in fathers was associated with more PPD symptoms in those fathers but fewer PPD symptoms in their partners. Generally, however, the literature on the hormonal correlates of PPD has been small and fairly inconclusive (Yim et al., 2015). Similarly, work on the neural correlates of perinatal mood disorders has lagged behind many other areas of investigation. A 2017 review estimated that 17 human brain imaging studies of postpartum depression have been conducted to date, far fewer than within many other areas of psychopathology (Pawluski, Lonstein, \& Fleming, 2017). Given its tremendous public health importance, understanding the neurobiological underpinnings of postpartum depression should be a high scientific priority.

In addition to hormonal and neural mechanisms, psychological and behavioral mechanisms contribute to mood disorder risk over the transition to parenthood. Psychosocial stress and parenting stress appear to worsen PPD (Vismara et al., 2016). One study that followed mothers from one postpartum period to a subsequent postpartum period found that self-reported stress between pregnancies mediated the association between depressive symptoms across the two postpartum periods (Dunkel Schetter, Saxbe, Cheadle, \& Guardino, 2016). Similarly, lack of physical exercise and sleep disturbance may aggravate depressive symptoms (Bhati \& Richards, 2015; Lawson, Murphy, Sloan, Uleryk, \& Dalfen, 2015). For example, a longitudinal study found associations between sleep and PPD in both mothers and fathers, such that parental sleep problems in the first 6 months after birth appeared to exacerbate PPD over the first year postpartum and helped explain the transmission of PPD within couples (Saxbe et al., 2016).

\section{The Transition to Parenthood: An Inflection Point for Health Disparities?}

The field of health disparities research has evolved from studying income-health gradients to exploring the mecha- nisms underlying these gradients from a multilevel and interactional perspective (Adler \& Stewart, 2010). Many of the mechanisms discussed in this article have been tied to population-level health disparities. For example, a large study of adults in midlife found that poor sleep quality in African Americans (particularly women) explained half of the racial differences in cardiometabolic risk (Curtis, FullerRowell, El-Sheikh, Carnethon, \& Ryff, 2017). Higher BMI trajectories across the life span among low-SES individuals are consistently shown in epidemiological studies (Clarke, O'Malley, Johnston, Schulenberg, \& Lantz, 2009), and lowSES individuals show more dysregulated profiles of physiological stress and inflammation (Koster et al., 2006). Despite this large and growing literature, few studies of health disparities have focused specifically on the transition to parenthood. In particular, differences in PFL access may be an especially salient socioeconomic inequity for new parents in the United States with potentially long-term consequences for allostatic load, obesity, and mood disorders as well as implications for parenting and parent-child bonding.

\section{Paid Family Leave (PFL) and Health Over the Transition to Parenthood}

Incompatibility between work and family life has been associated with parental depression, poor physical health, poor health behaviors, and worse sleep quality (Allen \& Armstrong, 2006). Here, we focus on family leave as a potential policy response that may mitigate some of the mental and physical health challenges associated with the transition into parenthood. What is the current landscape regarding family leave in the United States, and what is the evidence on the impacts of leave policies on family health outcomes?

As mentioned, the United States grants 12 weeks of job-protected unpaid leave via the Family Medical Leave Act (FMLA, 2006). Regarding paid leave, as mentioned, the United States is unique among industrialized countries in offering no family leave provisions at the federal level. At the state level, birth mothers (but not fathers or adoptive parents) have been eligible for several weeks of paid leave through state temporary disability insurance (TDI) programs since the 1978 The Pregnancy Discrimination Act, (1978) in five states (California, Hawaii, New Jersey, New York, and Rhode Island). In 2004, California became the first state to implement a PFL policy that covers all parents of newborn or adopted children (as well as caregivers of ill family members). Since then, New Jersey (in 2009), Rhode Island (in 2014), and New York (in 2018) have followed. Washington state and Washington, DC, have also passed PFL legislation, with programs to go into effect in 2020. These existing state-level PFL laws all provide partial wage replacement during leave and cover a broad segment of the 
workforce through minimal eligibility requirements, but they differ on distinct policy levers, including statutory leave duration, benefit amount, job protection, and funding mechanism. For example, the number of weeks of PFL range from 4 weeks (in Rhode Island) to 12 weeks (in New York and Washington state).

A large body of research has been dedicated to understanding how PFL affects women's career trajectories and whether it diminishes the widely documented motherhood wage penalty (e.g., Kleven, Landais, \& Søgaard, 2018). Broadly speaking, leave durations shorter than 1 year tend to have zero or small positive effects on women's subsequent labor market outcomes, whereas paid leave beyond 1 year can depress mothers' wages in the long run (RossinSlater, 2018). Moreover, most employers report either positive or neutral effects of PFL on productivity, morale, and costs (Milkman \& Appelbaum, 2013). In this article we have argued that, in addition to labor market outcomes, PFL may affect parent health. However, data linking PFL with health measures is not typically collected in commonly used survey data sets in the United States. Additionally, access to PFL is not random: More advantaged workers are much more likely to have access to and use PFL benefits than are their less advantaged counterparts, making it difficult to isolate the causal effects of paid leave from the influence of the many other factors that also impact family outcomes.

Despite these challenges, longer maternity leaves do appear to correlate with improvements in maternal health. Aitken et al. (2015) reviewed seven studies from Australia, Norway, Sweden, Canada, the United States, and Lebanon and found that longer paid leave was associated with mothers' reports of greater mental and physical well-being, including reduced depression risk and better self-reported general physical health. Butikofer, Riise, and Skira (2018) leveraged a natural experiment from a policy reform in Norway that provided all mothers of children born on July 1, 1977, or later with 4 months of paid maternity leave in addition to the 12 months of unpaid leave that were already provided. Butikofer and colleagues compared mothers of children born shortly before and shortly after this reform, finding that access to longer leave causes improved longterm maternal health measured around age 40, an average of 15 years following the birth. They documented beneficial effects for a number of outcomes, including BMI, obesity, blood pressure, pain, and self-reported mental health.

In the United States, one study suggested that even the introduction of 12 weeks of unpaid leave can improve child health: Rossin (2011) analyzed the impacts of the implementation of the FMLA, finding that it led to a small increase in birth weight and a large reduction in the infant mortality rate. The health benefits of the FMLA accrued to children of only highly educated, married mothers, however, likely due to their being most likely to be eligible for FMLA and able to afford to take unpaid time off. In con- trast, Stearns (2015) examined the 1978 introduction of about 6 weeks of paid maternity leave in five states through the TDI system. She documented that TDI coverage of maternity benefits lowered rates of low birth weight and preterm births. Unlike the case in Rossin's (2011) study, these impacts were largest among disadvantaged African American and unmarried mothers, implying that paid and unpaid leave policies benefit different populations. Both of these studies focused on infant health, leaving open the question of how state-by-state PFL policies affect parental well-being.

When it comes to fathers, most evidence has focused on how policies impact paternity leave take-up, which lags behind leave use among mothers. For instance, Bana, Bedard, and Rossin-Slater (2018) documented that in 2014-10 years after the introduction of California's PFL (CA-PFL) - only $12 \%$ of employed fathers of infants took PFL, compared to an estimated $47 \%$ of mothers. That said, CA-PFL substantially increased paternity leave take-up when compared to the case with fathers in other states and fathers of children born before the policy (e.g., Bartel, Rossin-Slater, Ruhm, \& Waldfogel, 2016). Recently, countries including Sweden, Norway, Germany, and Canada have implemented reforms that earmark a part of the general parental leave to fathers only. Although these reforms typically raise paternity leave take-up rates, impacts on paternal labor market outcomes and household time use are mixed (e.g., Ekberg, Eriksson, \& Friebel, 2013). There is little evidence on how paternity leave use affects fathers' health. One Swedish study showed that, among all fathers of firstborn children born in 1978, those who took paternity leave were less likely to have died by 2001 than were those who did not (Månsdotter, Lindholm, \& Winkvist, 2007). However, differences between fathers who did and did not choose to use paternity leave may confound these results. In sum, much more research is needed to understand the psychosocial and public health implications of both maternal and paternal parental leave.

\section{Conclusions}

Becoming a parent is fraught with challenge, risk, and growth. Although the field of developmental psychology has been traditionally circumscribed to childhood and adolescence, adults also undergo psychological and physical change-accompanied by shifting social roles, relationship dynamics, and neural and biological plasticity-across the life span. Conceptualizing the transition to parenthood as a critical window for health means that it may also be a time of greater susceptibility to the factors that contribute to health disparities. In this article, we focused on mood disorders, obesity, and allostatic load as areas of heightened health risk in new parents and identified PFL policies as a potential and yet understudied driver of socioeconomic disparities in the United States. We argue that the develop- 
mental psychology of parents warrants greater attention from both researchers and policymakers. Supporting new parents' transformation into competent caregivers may be the most important way to ensure healthy child development and protect children from the lifetime legacy of early stress (Shonkoff \& Fisher, 2013).

Research on the social determinants of population health has often concentrated on samples recruited in midlife and beyond, when risk for chronic cardiometabolic disease is highest. However, this may represent a missed opportunity for understanding health trajectories that may be inflected by the changes in stress, behavior, and even physiology that occur earlier in the life span, during the transition to parenthood. Past interventions directed toward adults in poverty (such as work readiness programs) have not been well integrated with interventions directed toward children. Increasingly, policymakers are adopting "2Gen" models that view adults as parents as well as resource providers (Kim \& Watamura, 2015). These models focus on building adults' capacity as caregivers of children. Given that parents' perinatal stress and depression have clear effects on child development, targeting parental well-being thus has the potential to disrupt the intergenerational transmission of socioeconomic risk (Shonkoff \& Fisher, 2013).

Many two-generation intervention programs have focused on improving parenting skills and addressing potential problems (such as child behavior problems or parental psychopathology) that may disrupt the parent-child bond. For example, the Filming Interactions to Nurture Development program uses video coaching to encourage parents' sensitivity and perspective-taking (Fisher, Frenkel, Noll, Berry, \& Yockelson, 2016). Home visiting programs such as the Nurse-Family Partnership in the United States and the kraamverzorgster (postpartum care professional) model in the Netherlands allow for earlier detection of potential concerns and have been associated with both better family health outcomes (Kim \& Watamura, 2015).

These programs have tremendous value, but we argue that parenting skill development and coaching represent several steps down the road from a broader and more basic public health goal: stress reduction in the perinatal period and time for parents and children to bond. For the $25 \%$ of U.S. women who take less than 2 weeks off from paid work after childbirth, more time to rest, recover, and get to know their new infant may yield dramatic benefits. If public health interventions are framed in terms of a pyramid, with broader population-based initiatives at the bottom and individualized counseling at the top (Frieden, 2010), PFL would be near the base, with the potential to influence key social determinants of health and reduce the need for costly intervention later on. Family leave policies have received relatively little attention from health psychologists or neuroscientists but can help working parents navigate changing roles, routines, and responsibilities after the arrival of a new child. Psychological scientists can make important contributions to understanding the psychological impact of PFL and quantifying the health costs and benefits of PFL policies. Mechanistically informed research designs that use innovative approaches to characterize the impact of PFL on the changing parental body and brain are sorely needed. Psychologists can also use their expertise on stress and mental health to advocate for PFL policies that reduce parental burnout and ameliorate risks to families and to help design and recommend policies for PFL (along with sick leave and other workplace measures) that are responsive to parent and child well-being.

Social connection has been identified within these pages as a public health priority (Holt-Lunstad, Robles, \& Sbarra, 2017). In their American Psychologist article, Holt-Lunstad and her coauthors (2017) argued that the prevalence and costs of social disconnection exceed the costs of smoking, alcohol consumption, and obesity but that social connection has received far fewer public health resources. We would extend this argument to argue for a specific focus on new parents, given that parent-child relationships are among the first and most important social relationships. Policies that reduce stress on parents and protect the parent-child bond can reverberate through families, workplaces, and societies and resonate for generations. Although the decision to have children is a personal choice, children are also a public good. Conceptualizing the transition to parenthood as a critical window for family health may help to underscore the need for significant social investment during a time of transformation and potential fragility for both parents and children.

\section{References}

Abraham, E., Hendler, T., Shapira-Lichter, I., Kanat-Maymon, Y., Zagoory-Sharon, O., \& Feldman, R. (2014). Father's brain is sensitive to childcare experiences. Proceedings of the National Academy of Sciences of the United States of America, 111, 9792-9797. http://dx.doi.org/10 .1073/pnas.1402569111

Acebo, C., Sadeh, A., Seifer, R., Tzischinsky, O., Hafer, A., \& Carskadon, M. A. (2005). Sleep/wake patterns derived from activity monitoring and maternal report for healthy 1- to 5-year-old children. Sleep, 28, 1568 1577. http://dx.doi.org/10.1093/sleep/28.12.1568

Adler, N. E., \& Stewart, J. (2010). Health disparities across the lifespan: Meaning, methods, and mechanisms. Annals of the New York Academy of Sciences, 1186, 5-23. http://dx.doi.org/10.1111/j.1749-6632.2009.05337.x

Aitken, Z., Garrett, C. C., Hewitt, B., Keogh, L., Hocking, J. S., \& Kavanagh, A. M. (2015). The maternal health outcomes of paid maternity leave: A systematic review. Social Science \& Medicine, 130, 32-41. http://dx.doi.org/10.1016/j.socscimed.2015.02.001

Allen, T. D., \& Armstrong, J. (2006). Further examination of the link between work-family conflict and physical health: The role of healthrelated behaviors. American Behavioral Scientist, 49, 1204-1221. http:// dx.doi.org/10.1177/0002764206286386

Amorim, A. R., Rössner, S., Neovius, M., Lourenço, P. M., \& Linné, Y. (2007). Does excess pregnancy weight gain constitute a major risk for increasing long-term BMI? Obesity, 15, 1278-1286. http://dx.doi.org/ 10.1038/oby.2007.149

Baker, J. L., Gamborg, M., Heitmann, B. L., Lissner, L., Sørensen, T. I., \& Rasmussen, K. M. (2008). Breastfeeding reduces postpartum weight 
retention. American Journal of Clinical Nutrition, 88, 1543-1551. http:// dx.doi.org/10.3945/ajen.2008.26379

Bana, S., Bedard, K., \& Rossin-Slater, M. (2018). Trends and Disparities in Leave Use under California's Paid Family Leave Program: New Evidence from Administrative Data. AEA Papers and Proceedings, 108, 388-391. http://dx.doi.org/10.1257/pandp.20181113

Bartel, A., Rossin-Slater, M., Ruhm, C., \& Waldfogel, J. (2016). Assessing Rhode Island's Temporary Caregiver Insurance Act: Insights from a survey of employers. Washington, DC: U.S. Department of Labor.

Bellows-Riecken, K. H., \& Rhodes, R. E. (2008). A birth of inactivity? A review of physical activity and parenthood. Preventive Medicine, 46, 99-110. http://dx.doi.org/10.1016/j.ypmed.2007.08.003

Belsky, J., \& Rovine, M. (1990). Patterns of marital change across the transition to parenthood: Pregnancy to three years postpartum. Journal of Marriage and the Family, 52, 5-19. http://dx.doi.org/10.2307/352833

Berge, J. M., Larson, N., Bauer, K. W., \& Neumark-Sztainer, D. (2011). Are parents of young children practicing healthy nutrition and physical activity behaviors? Pediatrics, 127, 881-887. http://dx.doi.org/10.1542/ peds.2010-3218

Bhati, S., \& Richards, K. (2015). A systematic review of the relationship between postpartum sleep disturbance and postpartum depression. Journal of Obstetric, Gynecologic, and Neonatal Nursing, 44, 350-357. http://dx.doi.org/10.1111/1552-6909.12562

Brunton, P. J., \& Russell, J. A. (2008). The expectant brain: Adapting for motherhood. Nature Reviews Neuroscience, 9, 11-25. http://dx.doi.org/ $10.1038 / \mathrm{nrn} 2280$

Bureau of Labor Statistics. (2015). Labor force statistics from the current population survey. Retrieved from https://www.bls.gov/cps/cpsaat03 .htm

Butikofer, A., Riise, J., \& Skira, M. (2018). The Impact of Paid Maternity Leave on Maternal Health. SSRN Electronic Journal. Advance online publication. http://dx.doi.org/10.2139/ssrn.3139823

Christian, L. M., Kowalsky, J. M., Mitchell, A. M., \& Porter, K. (2018). Associations of postpartum sleep, stress, and depressive symptoms with LPS-stimulated cytokine production among African American and White women. Journal of Neuroimmunology, 316, 98-106. http://dx.doi .org/10.1016/j.jneuroim.2017.12.020

Clarke, P. J., O’Malley, P. M., Johnston, L. D., Schulenberg, J. E., \& Lantz, P. (2009). Differential trends in weight-related health behaviors among American young adults by gender, race/ethnicity, and socioeconomic status: 1984-2006. American Journal of Public Health, 99, 1893-1901. http://dx.doi.org/10.2105/AJPH.2008.141317

Cowan, C. P., \& Cowan, P. A. (2000). When partners become parents: The big life change for couples. Mahwah, NJ: Erlbaum.

Curtis, D. S., Fuller-Rowell, T. E., El-Sheikh, M., Carnethon, M. R., \& Ryff, C. D. (2017). Habitual sleep as a contributor to racial differences in cardiometabolic risk. Proceedings of the National Academy of Sciences of the United States of America, 114, 8889-8894. http://dx.doi .org/10.1073/pnas.1618167114

Dahl, R., Suleiman, A., Luna, B., Choudhury, S., Noble, K., Lupien, S. J., . . Uncapher, M. R. (2017). The adolescent brain: A second window of opportunity. Florence, Italy: UNICEF Office of Research.

Denney, J. M., Nelson, E. L., Wadhwa, P. D., Waters, T. P., Mathew, L., Chung, E. K., . . . Culhane, J. F. (2011). Longitudinal modulation of immune system cytokine profile during pregnancy. Cytokine, 53, 170-177.

Dunkel Schetter, C. D., Saxbe, D., Cheadle, A., \& Guardino, C. (2016). Postpartum depressive symptoms following consecutive pregnancies: Stability, change, and mechanisms. Clinical Psychological Science, 4, 909-918. http://dx.doi.org/10.1177/2167702616644894

Ekberg, J., Eriksson, R., \& Friebel, G. (2013). Parental leave-A policy evaluation of the Swedish "Daddy-Month" reform. Journal of Public Economics, 97, 131-143. http://dx.doi.org/10.1016/j.jpubeco.2012.09.001

Family and Medical Leave Act of 1993, 29 U.S.C. $§ \$ 2601-2654$ (2006).
Filtness, A. J., MacKenzie, J., \& Armstrong, K. (2014). Longitudinal change in sleep and daytime sleepiness in postpartum women. PLoS ONE, 9(7), e103513. http://dx.doi.org/10.1371/journal.pone.0103513

Fisher, P. A., Frenkel, T. I., Noll, L. K., Berry, M., \& Yockelson, M. (2016). Promoting healthy child development via a two-generation translational neuroscience framework: The Filming Interactions to Nurture Development video coaching program. Child Development Perspectives, 10, 251-256. http://dx.doi.org/10.1111/cdep.12195

Frieden, T. R. (2010). A framework for public health action: The health impact pyramid. American Journal of Public Health, 100, 590-595. http://dx.doi.org/10.2105/AJPH.2009.185652

Fuligni, A. J., Dapretto, M., \& Galván, A. (2018). Broadening the impact of developmental neuroscience on the study of adolescence. Journal of Research on Adolescence, 28, 150-153. http://dx.doi.org/10.1111/jora .12373

Gay, C. L., Lee, K. A., \& Lee, S.-Y. (2004). Sleep patterns and fatigue in new mothers and fathers. Biological Research for Nursing, 5, 311-318. http://dx.doi.org/10.1177/1099800403262142

Genesoni, L., \& Tallandini, M. A. (2009). Men's psychological transition to fatherhood: An analysis of the literature, 1989-2008. Birth: Issues in Perinatal Care, 36, 305-318. http://dx.doi.org/10.1111/j.1523-536X 2009.00358.x

Gettler, L. T., McDade, T. W., Feranil, A. B., \& Kuzawa, C. W. (2011). Longitudinal evidence that fatherhood decreases testosterone in human males. Proceedings of the National Academy of Sciences of the United States of America, 108, 16194-16199. http://dx.doi.org/10.1073/pnas 1105403108

Gettler, L. T., Sarma, M. S., Gengo, R. G., Oka, R. C., \& McKenna, J. J. (2017). Adiposity, CVD risk factors and testosterone: Variation by partnering status and residence with children in U.S. men. Evolution, Medicine, and Public Health, 2017, 67-80. http://dx.doi.org/10.1093/ emph/eox005

Gillespie, S. L., Porter, K., \& Christian, L. M. (2016). Adaptation of the inflammatory immune response across pregnancy and postpartum in Black and White women. Journal of Reproductive Immunology, 114, 27-31. http://dx.doi.org/10.1016/j.jri.2016.02.001

Guardino, C. M., Dunkel Schetter, C., Hobel, C. J., Gaines Lanzi, R., Schafer, P., Thorp, J. M., \& Shalowitz, M. U. (2017). Chronic stress and C-reactive protein in mothers during the first postpartum year. Psychosomatic Medicine, 79, 450-460. http://dx.doi.org/10.1097/PSY .0000000000000424

Guardino, C. M., Dunkel Schetter, C., Saxbe, D. E., Adam, E. K., Ramey, S. L., \& Shalowitz, M. U. (2016). Diurnal salivary cortisol patterns prior to pregnancy predict infant birth weight. Health Psychology, 35, 625633. http://dx.doi.org/10.1037/hea0000313

Hagen, E. W., Mirer, A. G., Palta, M., \& Peppard, P. E. (2013). The sleep-time cost of parenting: Sleep duration and sleepiness among employed parents in the Wisconsin Sleep Cohort Study. American Journal of Epidemiology, 177, 394-401. http://dx.doi.org/10.1093/aje/kws246

Harkness, K. L., \& Monroe, S. M. (2016). The assessment and measurement of adult life stress: Basic premises, operational principles, and design requirements. Journal of Abnormal Psychology, 125, 727-745. http://dx.doi.org/10.1037/abn0000178

Hill, B., Skouteris, H., McCabe, M., Milgrom, J., Kent, B., Herring, S. J., . . Gale, J. (2013). A conceptual model of psychosocial risk and protective factors for excessive gestational weight gain. Midwifery, 29, 110-114. http://dx.doi.org/10.1016/j.midw.2011.12.001

Hoekzema, E., Barba-Müller, E., Pozzobon, C., Picado, M., Lucco, F., García-García, D., . . . Vilarroya, O. (2017). Pregnancy leads to longlasting changes in human brain structure. Nature Neuroscience, 20, 287-296. http://dx.doi.org/10.1038/nn.4458

Holt-Lunstad, J., Robles, T. F., \& Sbarra, D. A. (2017). Advancing social connection as a public health priority in the United States. American Psychologist, 72, 517-530. http://dx.doi.org/10.1037/amp0000103 
Hull, E. E., Rofey, D. L., Robertson, R. J., Nagle, E. F., Otto, A. D., \& Aaron, D. J. (2010). Influence of marriage and parenthood on physical activity: A 2-year prospective analysis. Journal of Physical Activity \& Health, 7, 577-583. http://dx.doi.org/10.1123/jpah.7.5.577

Juster, R. P., McEwen, B. S., \& Lupien, S. J. (2010). Allostatic load biomarkers of chronic stress and impact on health and cognition. Neuroscience and Biobehavioral Reviews, 35, 2-16. http://dx.doi.org/10 .1016/j.neubiorev.2009.10.002

Kim, P., Capistrano, C., \& Congleton, C. (2016). Socioeconomic disadvantages and neural sensitivity to infant cry: Role of maternal distress. Social Cognitive and Affective Neuroscience, 11, 1597-1607. http://dx .doi.org/10.1093/scan/nsw063

Kim, P., Capistrano, C. G., Erhart, A., Gray-Schiff, R., \& Xu, N. (2017). Socioeconomic disadvantage, neural responses to infant emotions, and emotional availability among first-time new mothers. Behavioural Brain Research, 325, 188-196. http://dx.doi.org/10.1016/j.bbr.2017.02.001

Kim, P., Leckman, J. F., Mayes, L. C., Feldman, R., Wang, X., \& Swain, J. E. (2010). The plasticity of human maternal brain: Longitudinal changes in brain anatomy during the early postpartum period. Behavioral Neuroscience, 124, 695-700. http://dx.doi.org/10.1037/a0020884

Kim, P., Rigo, P., Mayes, L. C., Feldman, R., Leckman, J. F., \& Swain, J. E. (2014). Neural plasticity in fathers of human infants. Social Neuroscience, 9, 522-535. http://dx.doi.org/10.1080/17470919.2014 .933713

Kim, P., Strathearn, L., \& Swain, J. E. (2016). The maternal brain and its plasticity in humans. Hormones and Behavior, 77, 113-123. http://dx .doi.org/10.1016/j.yhbeh.2015.08.001

Kim, P., \& Watamura, S. E. (2015). Two open windows: Infant and parent neurobiologic change. Retrieved from https://ascend.aspeninstitute.org/ resources/two-open-windows-infant-and-parent-neurobiologic-change-2/

Kleven, H., Landais, C., \& Søgaard, J. E. (2018). Children and gender inequality: Evidence from Denmark (NBER Working Paper No. 24219). http://dx.doi.org/10.3386/w24219

Koster, A., Bosma, H., Penninx, B. W., Newman, A. B., Harris, T. B., van Eijk, J. T. M., . . Kritchevsky, S. B. (2006). Association of inflammatory markers with socioeconomic status. Journals of Gerontology: Series A. Biological Sciences and Medical Sciences, 61, 284-290. http://dx.doi .org/10.1093/gerona/61.3.284

Kuo, P. X., Carp, J., Light, K. C., \& Grewen, K. M. (2012). Neural responses to infants linked with behavioral interactions and testosterone in fathers. Biological Psychology, 91, 302-306. http://dx.doi.org/10 .1016/j.biopsycho.2012.08.002

Laurent, H. K., \& Ablow, J. C. (2013). A face a mother could love: Depression-related maternal neural responses to infant emotion faces. Social Neuroscience, 8, 228-239. http://dx.doi.org/10.1080/17470919 2012.762039

Lawson, A., Murphy, K. E., Sloan, E., Uleryk, E., \& Dalfen, A. (2015). The relationship between sleep and postpartum mental disorders: A systematic review. Journal of Affective Disorders, 176, 65-77. http://dx .doi.org/10.1016/j.jad.2015.01.017

LeMasters, E. E. (1957). Parenthood as crisis. Marriage and family living, $19,352-355$

Månsdotter, A., Lindholm, L., \& Winkvist, A. (2007). Paternity leave in Sweden: Costs, savings and health gains. Health Policy, 82, 102-115. http://dx.doi.org/10.1016/j.healthpol.2006.09.006

Marcus, S. M. (2009). Depression during pregnancy: Rates, risks and consequences-Motherisk Update 2008. Canadian Journal of Clinical Pharmacology, 16(1), e15-e22.

Margolis, R., \& Myrskylä, M. (2015). Parental well-being surrounding first birth as a determinant of further parity progression. Demography, 52, 1147-1166. http://dx.doi.org/10.1007/s13524-015-0413-2

Marshall, N. L., \& Tracy, A. J. (2009). After the baby: Work-family conflict and working mothers' psychological health. Family Relations, 58, 380-391. http://dx.doi.org/10.1111/j.1741-3729.2009.00560.x
Milkman, R., \& Appelbaum, E. (2013). Unfinished business: Paid family leave in California and the future of U.S. work-family policy. $\mathrm{http}: / / \mathrm{dx}$ .doi.org/10.7591/cornel1/9780801452383.001.0001

Moen, P., \& Orrange, R. M. (2002). Careers and lives socialization, structural lag, and gendered ambivalence. Advances in Life Course Research, 7, 231-260. http://dx.doi.org/10.1016/S1040-2608(02)80036-3

Monroe, S. M., \& Harkness, K. L. (2005). Life stress, the "kindling" hypothesis, and the recurrence of depression: considerations from a life stress perspective. Psychological review, 112, 417.

Murray, L., \& Cooper, P. J. (1997). Postpartum depression and child development. Psychological Medicine, 27, 253-260. http://dx.doi.org/10 1017/S0033291796004564

Nasuti, G., Blanchard, C., Naylor, P. J., Levy-Milne, R., Warburton, D. E., Benoit, C., . . . Rhodes, R. E. (2014). Comparison of the dietary intakes of new parents, second-time parents, and nonparents: A longitudinal cohort study. Journal of the Academy of Nutrition and Dietetics, 114, 450-456. http://dx.doi.org/10.1016/j.jand.2013.07.042

O'Hara, M. W., \& McCabe, J. E. (2013). Postpartum depression: Current status and future directions. Annual Review of Clinical Psychology, 9, 379-407. http://dx.doi.org/10.1146/annurev-clinpsy-050212-185612

Paulson, J. F., \& Bazemore, S. D. (2010). Prenatal and postpartum depression in fathers and its association with maternal depression: A metaanalysis. Journal of the American Medical Association, 303, 1961-1969. http://dx.doi.org/10.1001/jama.2010.605

Pawluski, J. L., Lonstein, J. S., \& Fleming, A. S. (2017). The neurobiology of postpartum anxiety and depression. Trends in Neurosciences, 40, 106-120. http://dx.doi.org/10.1016/j.tins.2016.11.009

Pedersen, P., Baker, J. L., Henriksen, T. B., Lissner, L., Heitmann, B. L., Sørensen, T. I., \& Nohr, E. A. (2011). Influence of psychosocial factors on postpartum weight retention. Obesity, 19, 639-646. http://dx.doi.org/ 10.1038/oby.2010.175

Ramchandani, P., Stein, A., Evans, J., O'Connor, T. G., \& The ALSPAC Study Team. (2005, June 25). Paternal depression in the postnatal period and child development: A prospective population study. Lancet, 365, 2201-2205. http://dx.doi.org/10.1016/S0140-6736(05)66778-5

Reid, K. M., \& Taylor, M. G. (2015). Social support, stress, and maternal postpartum depression: A comparison of supportive relationships. Social Science Research, 54, 246-262. http://dx.doi.org/10.1016/j.ssresearch 2015.08.009

Rhoades, G. K., Stanley, S. M., \& Markman, H. J. (2012). A longitudinal investigation of commitment dynamics in cohabiting relationships. Jour nal of Family Issues, 33, 369-390. http://dx.doi.org/10.1177/0192513X11 420940

Rhodes, R. E., Blanchard, C. M., Benoit, C., Levy-Milne, R., Naylor, P. J., Symons Downs, D., \& Warburton, D. E. (2014). Physical activity and sedentary behavior across 12 months in cohort samples of couples without children, expecting their first child, and expecting their second child. Journal of Behavioral Medicine, 37, 533-542. http://dx.doi.org/ 10.1007/s10865-013-9508-7

Rossi, A. S. (1968). Transition to parenthood. Journal of Marriage and the Family, 30, 26-39. http://dx.doi.org/10.2307/350219

Rossin, M. (2011). The effects of maternity leave on children's birth and infant health outcomes in the United States. Journal of Health Economics, 30, 221-239. http://dx.doi.org/10.1016/j.jhealeco.2011.01.005

Rossin-Slater, M. (2018). Maternity and family leave policy. In S. L. Averett, L. M. Argys, \& S. D. Hoffman (Eds.), The Oxford handbook of women and the economy (pp. 323-344). New York, NY: Oxford University Press.

Sapolsky, R. M. (2004). Why zebras don't get ulcers (3rd ed.). New York, NY: Holt Paperbacks.

Saxbe, D. E., Adam, E. K., Dunkel Schetter, C., Guardino, C. M., Simon, C., McKinney, C. O., . . . Eunice Kennedy Shriver National Institute for Child Health and Human Development (NICHD) Community Child Health Network (CCHN). (2015). Cortisol covariation within parents of 
young children: Moderation by relationship aggression. Psychoneuroendocrinology, 62, 121-128. http://dx.doi.org/10.1016/j.psyneuen.2015.08 .006

Saxbe, D. E., Repetti, R. L., \& Graesch, A. P. (2011). Time spent in housework and leisure: Links with parents' physiological recovery from work. Journal of Family Psychology, 25, 271-281. http://dx.doi.org/10 $.1037 / \mathrm{a} 0023048$

Saxbe, D. E., Dunkel Schetter, C., Guardino, C. M., Ramey, S. L., Shalowitz, M. U., Thorp, J., . . Eunice Kennedy Shriver National Institute for Child Health and Human Development Community Child Health Network. (2016). Sleep quality predicts persistence of parental postpartum depressive symptoms and transmission of depressive symptoms from mothers to fathers. Annals of Behavioral Medicine, 50, 862-875. http://dx.doi.org/10.1007/s12160-016-9815-7

Saxbe, D. E., Dunkel Schetter, C., Simon, C. D., Adam, E. K., \& Shalowitz, M. U. (2017). High paternal testosterone may protect against postpartum depressive symptoms in fathers, but confer risk to mothers and children. Hormones and Behavior, 95, 103-112. http://dx.doi.org/10 .1016/j.yhbeh.2017.07.014

Scott, J. A., Binns, C. W., Oddy, W. H., \& Graham, K. I. (2006). Predictors of breastfeeding duration: Evidence from a cohort study. Pediatrics, 117, e646-e655. http://dx.doi.org/10.1542/peds.2005-1991

Seeman, T. E., McEwen, B. S., Rowe, J. W., \& Singer, B. H. (2001). Allostatic load as a marker of cumulative biological risk: MacArthur studies of successful aging. Proceedings of the National Academy of Sciences of the United States of America, 98, 4770-4775. http://dx.doi .org/10.1073/pnas.081072698

Shonkoff, J. P., \& Fisher, P. A. (2013). Rethinking evidence-based practice and two-generation programs to create the future of early childhood policy. Development and Psychopathology, 25, 1635-1653. http://dx.doi .org/10.1017/S0954579413000813

Siega-Riz, A. M., Herring, A. H., Carrier, K., Evenson, K. R., Dole, N., \& Deierlein, A. (2010). Sociodemographic, perinatal, behavioral, and psychosocial predictors of weight retention at 3 and 12 months postpartum. Obesity, 18, 1996-2003. http://dx.doi.org/10.1038/oby.2009.458

Simon, C. D., Adam, E. K., McKinney, C. O., Krohn, J. B., \& Shalowitz, M. U. (2016). Breastfeeding, bed-sharing, and maternal cortisol. Clinical Pediatrics, 55, 470-478. http://dx.doi.org/10.1177/0009922815601981

Sisk, C. L., \& Zehr, J. L. (2005). Pubertal hormones organize the adolescent brain and behavior. Frontiers in Neuroendocrinology, 26, 163-174. http://dx.doi.org/10.1016/j.yfrne.2005.10.003

Slatcher, R. B., Robles, T. F., Repetti, R. L., \& Fellows, M. D. (2010). Momentary work worries, marital disclosure, and salivary cortisol among parents of young children. Psychosomatic Medicine, 72, 887896. http://dx.doi.org/10.1097/PSY.0b013e3181f60fcc

Sorrells, S. F., Paredes, M. F., Cebrian-Silla, A., Sandoval, K., Qi, D., Kelley, K. W., . . . Alvarez-Buylla, A. (2018, March 7). Human hippocampal neurogenesis drops sharply in children to undetectable levels in adults. Nature, 555, 377-381. http://dx.doi.org/10.1038/nature25975

Stearns, J. (2015). The effects of paid maternity leave: Evidence from Temporary Disability Insurance. Journal of Health Economics, 43, 85102. http://dx.doi.org/10.1016/j.jhealeco.2015.04.005

Storey, A. E., Walsh, C. J., Quinton, R. L., \& Wynne-Edwards, K. E. (2000). Hormonal correlates of paternal responsiveness in new and expectant fathers. Evolution and Human Behavior, 21, 79-95. http://dx .doi.org/10.1016/S1090-5138(99)00042-2

Stowe, Z. N., \& Nemeroff, C. B. (1995). Women at risk for postpartumonset major depression. American Journal of Obstetrics and Gynecology, 173, 639-645. http://dx.doi.org/10.1016/0002-9378(95)90296-1

Straub, H., Simon, C., Plunkett, B. A., Endres, L., Adam, E. K., Mckinney, C., . . Shalowitz, M. (2016). Evidence for a complex relationship among weight retention, cortisol and breastfeeding in postpartum women. Maternal and Child Health Journal, 20, 1375-1383. http://dx.doi .org/10.1007/s10995-016-1934-z

Swain, J. E., Lorberbaum, J. P., Kose, S., \& Strathearn, L. (2007). Brain basis of early parent-infant interactions: Psychology, physiology, and in vivo functional neuroimaging studies. Journal of Child Psychology and Psychiatry, 48, 262-287. http://dx.doi.org/10.1111/j.1469-7610.2007.01731.x

The Pregnancy Discrimination Act, 42 US Code Chapter $21 \S 701$ (k) of Civil Rights Act of 1964 Title VII (1978).

Umberson, D., Liu, H., Mirowsky, J., \& Reczek, C. (2011). Parenthood and trajectories of change in body weight over the life course. Social Science \& Medicine, 73, 1323-1331. http://dx.doi.org/10.1016/j.socscimed.2011 .08 .014

U.S. Department of Labor. (2012). National Compensation Survey: Employee benefits in the United States, March 2012 (Bulletin No. 2773). Retrieved from www.bls.gov/ncs/ebs/benefits/2012/ebbl0050.pdf

van Scheppingen, M. A., Denissen, J. J. A., Chung, J. M., Tambs, K., \& Bleidorn, W. (2018). Self-esteem and relationship satisfaction during the transition to motherhood. Journal of Personality and Social Psychology, 114, 973-991. http://dx.doi.org/10.1037/pspp0000156

Vik, T., Grote, V., Escribano, J., Socha, J., Verduci, E., Fritsch, M., . . Koletzko, B. (2009). Infantile colic, prolonged crying and maternal postnatal depression. Acta Paediatrica, 98, 1344-1348. http://dx.doi .org/10.1111/j.1651-2227.2009.01317.x

Vismara, L., Rollè, L., Agostini, F., Sechi, C., Fenaroli, V., Molgora, S., ... Tambelli, R. (2016). Perinatal parenting stress, anxiety, and depression outcomes in first-time mothers and fathers: A 3- to 6-months postpartum follow-up study. Frontiers in Psychology, 7, 938. http://dx .doi.org/10.3389/fpsyg.2016.00938

Whitaker, K., Young-Hyman, D., Vernon, M., \& Wilcox, S. (2014). Maternal stress predicts postpartum weight retention. Maternal and Child Health Journal, 18, 2209-2217. http://dx.doi.org/10.1007/ s10995-014-1470-7

Wierenga, L. M., Bos, M. G. N., Schreuders, E., Vd Kamp, F., Peper, J. S., Tamnes, C. K., \& Crone, E. A. (2018). Unraveling age, puberty and testosterone effects on subcortical brain development across adolescence. Psychoneuroendocrinology, 91, 105-114. http://dx.doi.org/10 .1016/j.psyneuen.2018.02.034

Wonch, K. E., de Medeiros, C. B., Barrett, J. A., Dudin, A., Cunningham, W. A., Hall, G. B., . . Fleming, A. S. (2016). Postpartum depression and brain response to infants: Differential amygdala response and connectivity. Social Neuroscience, 11, 600-617. http://dx.doi.org/10.1080/ 17470919.2015.1131193

Xiao, R. S., Kroll-Desrosiers, A. R., Goldberg, R. J., Pagoto, S. L., Person, S. D., \& Waring, M. E. (2014). The impact of sleep, stress, and depression on postpartum weight retention: A systematic review. Journal of Psychosomatic Research, 77, 351-358. http://dx.doi.org/10.1016/ j.jpsychores.2014.09.016

Yim, I. S., Tanner Stapleton, L. R., Guardino, C. M., Hahn-Holbrook, J., \& Dunkel Schetter, C. (2015). Biological and psychosocial predictors of postpartum depression: Systematic review and call for integration. Annual Review of Clinical Psychology, 11, 99-137. http://dx.doi.org/10 $.1146 /$ annurev-clinpsy-101414-020426

Zijlmans, M. A., Riksen-Walraven, J. M., \& de Weerth, C. (2015). Associations between maternal prenatal cortisol concentrations and child outcomes: A systematic review. Neuroscience and Biobehavioral Reviews, 53, 1-24. http://dx.doi.org/10.1016/j.neubiorev.2015.02.015

Received April 9, 2018

Revision received July 31, 2018

Accepted July 31, 2018 